\title{
Mango seed kernel flour (Mangifera indica): nutrient composition and potential as food
}

\author{
Fajriyati Mas'ud ${ }^{1 *}$, Akhmad Rifai $^{1}$ \& Muhammad Sayuti ${ }^{2}$ \\ ${ }^{1}$ Department of Chemical Engineering, Politeknik Negeri Ujung Pandang, Makassar, \\ South Sulawesi, Indonesia; ${ }^{2}$ Agricultural Faculty, Gorontalo State University, \\ Gorontalo, Indonesia
}

\begin{abstract}
Introduction: Mango seed kernel flour (MSKF) is a potential source of nutrition and antioxidant. In the present paper, we provide a complete data on the nutrient compositions of seven varieties of MSKF that are grown in Indonesia. The data can be used as a reference when MSKF is used for further processing in a variety of products. Methods: Seven varieties of MSKF were analysed for their proximate composition, antioxidant components, mineral content, and fatty acid profile. Results: Carbohydrate, crude protein, total lipid, crude fibre, and ash contents of MSKF were found to be $36.2-39.3 \%, 5.2-6.6 \%, 5.9-7.2 \%, 2.2-2.5 \%$, and $2.9-5.5 \%$, respectively. MSKF contained a considerable amount of antioxidant components at $62.4-72.9 \mathrm{mg}$ total polyphenols $/ \mathrm{g}$, carotenoid of $1.3-2.4 \mathrm{mg} / 100 \mathrm{~g}$, vitamin $\mathrm{E}$ of $131.1-142.0 \mathrm{mg} / 100 \mathrm{~g}$, and ascorbic acid of $66.8-73.1 \mathrm{mg} / 100 \mathrm{~g}$. They also contained important minerals such as calcium at $25.2-36.8 \mathrm{mg} / 100 \mathrm{~g}$, magnesium at $82.7-124.2 \mathrm{mg} / 100 \mathrm{~g}$, potassium at $94.3-142.7 \mathrm{mg} / 100 \mathrm{~g}$, phosphorus at $72.7-95.3 \mathrm{mg} / 100 \mathrm{~g}$, and sodium at $21.7-37.5 \mathrm{mg} / 100 \mathrm{~g}$. Stearic acid was the main saturated fatty acid, while oleic acid was the major unsaturated fatty acid. Conclusion: MSKF has the potential to be a good source of nutrition for humans.
\end{abstract}

Keywords: Mango, proximate, antioxidant, fatty acid, minerals

\section{INTRODUCTION}

Mango seed is a by-product of the processing of mango fruit, and until now it is still often considered an agricultural waste. It is composed of a hard and thick endocarp which encloses a kernel. Mango seed is about $10-25 \%$ of the fruit's total weight, while $45-85 \%$ of the seed's weight is the kernel, which is approximately $20 \%$ of the weight of the whole fruit. Scientific studies have reported on the importance of nutrition that is contained in mango seed kernel (MSK), especially for feeding the ever-increasing human population. The problem of food insecurity in Asia and Africa in the next 35-50 years can cause hunger, and MSK is expected to help overcome this problem because it contains relatively high nutritional components.

In terms of anti-nutritional properties, the levels of phytic acid, hydrogen cyanide, and trypsin inhibitors are generally low and within the safe concentration which do not appear to pose a threat to life. The concentration

\footnotetext{
*Corresponding author: Dr Fajriyati Mas'ud

Department of Chemical Engineering, Politeknik Negeri Ujung Pandang, Makassar, 90245,

South Sulawesi, Indonesia.

Tel: +6281355033369; E-mail: fajri888@poliupg.ac.id

doi: https: / / doi.org/ 10.31246/mjn-2019-0082
} 
of these properties are below the concentration of $>20 \mathrm{mg} / 100 \mathrm{~g}$ that is considered as toxic.

In majority of the cases, by-products and even agricultural waste represent greater mass and often contain more active compounds. To fully exploit their biological potentials, by-products or waste with high nutritional content and functional values such as those contained in MSK can be used in the human diet. With the technology of nutritional preservation, mango seed kernel flour (MSKF) can be used as a composite flour or as a partial substitute for wheat flour in various food preparations, thus providing technological solutions. Related to the use of plant-based food sources as a composite flour for various food formulations, it is therefore essential to know more deeply the potential that is contained in MSKF.

Based on this purpose, this work aims to investigate more deeply the nutritional content of MSKF obtained from several different cultivars of mangoes grown in Indonesia. For the first time, this work investigates the potential of MSKF, which is critical as a preliminary study to provide data that are urgently needed by the highly developing food industry.

\section{MATERIALS AND METHODS}

\section{Materials}

Arumanis, Golek, Manalagi, Indramayu, Madu, Kemang, and Gedong Gincu varieties of mangoes cultivar in Indonesia were used in this study. All chemicals were sourced from Merck, Germany. The standard $\beta$-carotene was from Sigma (St. Louis, MO, USA), the standard $\alpha$-tocopherol was from SigmaAldrich $\mathrm{Co}$, and the standards for fatty acid methyl ester were from Supelco Inc., Bellefonte, PA (Supelco 37 Component FAME Mix).

\section{Sample preparation and composition analysis}

Preparation of MSKF samples were made according to Mas'ud et al. (2017). Proximate analyses i.e. moisture, protein, fat, fibre, and ash were carried out using the methods described in AOAC (1990). Carbohydrates were determined using the Luff-Schoorl method. Gas chromatography-mass spectrometry (GC-MS) was used to verify the fatty acids profile and vitamin $\mathrm{E}$ analysis. Total phenolic content was determined colorimetrically using the Folin-Ciocalteu's reagent method as described by Kriengsak et al. (2006). Ascorbic acid was determined by UVVisible Spectrophotometry, carotenoid analysis according to Karnjanawipagul et al. (2010), and mineral analysis by S2 Ranger X-ray Spectrometer, according to the user's manual XRF (2012) by Bruker AXS GmbH, Ostiche Rheinbruckenstr, 49.76187 Karlsruhe, Germany.

\section{RESULTS}

The results of the proximate composition, antioxidant compounds, and mineral compounds of the seven varieties of MSKF grown in Indonesia are presented in Table 1, while their fatty acids profiles are presented in Table 2 .

\section{DISCUSSION}

\section{Proximate composition}

The moisture, carbohydrate, crude protein, total lipid, crude fibre, and ash contents of MSKF were found to be $9.2-9.6 \%, 36.2-39.3 \%, \quad 5.2-6.6 \%$, $6.0-7.2 \%, \quad 2.2-2.5 \%$, and $2.9-5.5 \%$ on a dry weight basis, respectively. Related to the carbohydrate content, another study has reported that MSK contains carbohydrate of about 32.232.8\% (Nzikou et al., 2010). When compared to cassava and sweet potato, 

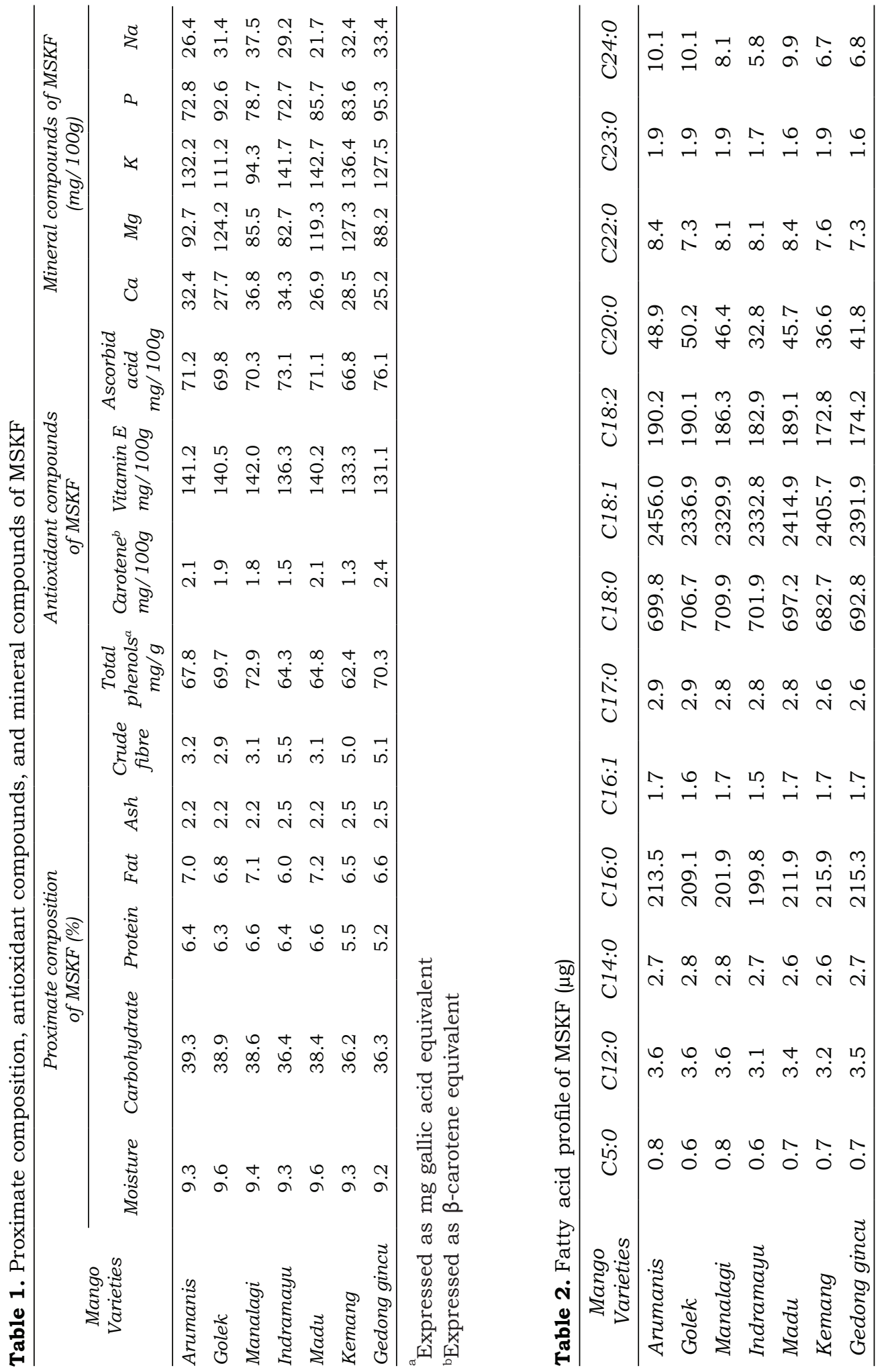
the carbohydrate content in MSK is equivalent to cassava and higher than a sweet potato. Even its protein and fat contents are higher. However, the fat content obtained in this study was lower than that shown by many other publications, maybe due to different mango varieties and differences in the location of growth.

In recent decades, mango seed lipids have attracted particular interest because they are a suitable source of fats that are beneficial to human health and nutrition. MSK fat has the typical characteristics of a vegetable butter (Muchiri, Mahungu \& Gituanja, 2012). Arumanis mango seed contains $7.0 \%$ oil (Mas'ud et al., 2017), which is rich in oleic and stearic acids. High stearic acid content makes mango seed oil have a semi-solid consistency; which can be used as a raw material for spreadable products. The lipid composition of MSK has also attracted the attention of scientists in recent years because of their unique physical and chemical characteristics. It is found that the physicochemical characteristics of mango seed fat are very similar to those of commercial cocoa butter (Jahurul et al., 2015), and its properties within the normal range of edible oils.

The fibre value was $1.9 \%$ higher than bush mango (Ekpe, Umoh \& Eka, 2007). MSKF contains high fibre, showing its potential as a good source of dietary fibre and plays an important role in reducing blood cholesterol levels. Based on the proximate composition analysis, it is known that MSK is a promising source of food.

According to Odunsi (2005), MSKF can be used in the manufacturing of cakes, cookies and breads for adults and children. Although MSKF cannot substitute maize, the composite flour application using MSKF and wheat flour or its combination with cassava or sweet potato flour in the manufacturing of cakes, cookies and breads is thought to be able to produce higher quality products in terms of nutritional content as this would increase the fat, protein, and phenolic contents.

\section{Antioxidant compounds}

Antioxidant components contained in the MSKF are presented in Table 1. MSKF contained $62.4-72.9 \mathrm{mg}$ of total polyphenols/g. Carotenoid ranged from $1.3-2.4 \mathrm{mg} / 100 \mathrm{~g}$, vitamin $\mathrm{E}$ 131.1-142.0mg/100g, and ascorbic acid $66.8-73.1 \mathrm{mg} / 100 \mathrm{~g}$. MSKF contained different phenolic compounds such as tannin, vanillin, coumarin, cinnamic, ferulic acids, mangiferin, gallic, and caffeic acids. The concentration of phenolic compounds in the seed kernels was 4.6 times higher than those in the pulp, making these promising residues a good polyphenolic source. MSKF contained six major phenolic compounds mainly gallic acid, ellagic acid, gallates, coumaric, vanillin, and ferulic acid. Mas'ud et al. (2017) reported that extracted oil from MSKF contained polyphenolics of $67.8 \mathrm{mg}$ GAE/g oil. The carotenoid values obtained in this study were around 1.3-2.4mg/100g; while other researchers have found it to be $0.79 \mathrm{mg} / 100 \mathrm{~g}$.

MSK could be used as a potential source for functional food ingredients due to its high quality of fat, as well as high levels of natural antioxidants. With the emergence of various diseases, the food industry is currently focused on the production of functional foods, and the nutritional potential and antioxidant content of MSKF are expected to be utilised optimally for the development of such products.

\section{Mineral compounds}

MSKF contained high amounts of potassium, phosphorus, and 
magnesium, depending on the variety (Table 1). The contents of calcium ranged from 25.2-36.8mg/100g, magnesium 82.7-124.2mg/100g, potassium 94.3-142.7mg/100g, phosphorus $72.7-95.3 \mathrm{mg} / 100 \mathrm{~g}$, and sodium $21.7-37.5 \mathrm{mg} / 100 \mathrm{~g}$. The calcium values obtained in this study were lower than the reported 49mg/100g (Elegbede, Achoba \& Richard, 1995) and 450mg/100g (Odunsi, 2005) for Nigeria mango, but higher than $10.2 \mathrm{mg} / 100 \mathrm{~g}$ (Nzikou et al., 2010). The magnesium values were lower than 980mg/100g (Odunsi, 2005) but higher than $22.3 \mathrm{mg} / 100 \mathrm{~g}$ (Nzikou et al., 2010). The potassium values were higher than 6mg/ 100g (Odunsi, 2005) but lower than 158mg/100g (Nzikou et al., 2010) and $365 \mathrm{mg} / 100 \mathrm{~g}$ (Elegbede, Achoba \& Richard, 1995). The phosphorus values were higher than 20mg/100g (Nzikou et al., 2010) but lower than 140mg/100g (Elegbede, Achoba \& Richard, 1995) and 230mg/100g (Odunsi, 2005). The sodium values were lower than $150 \mathrm{mg} / 100 \mathrm{~g}$ (Odunsi, 2005) but higher than $2.7 \mathrm{mg} / 100 \mathrm{~g}$ (Nzikou et al., 2010).

Mineral nutrition is very important, such as the need of potassium and phosphorus every day. Mango seed contains mineral compounds such as potassium, copper, zinc, manganese, iron, and selenium. The presence of mineral compounds has a crucial role in terms of food safety and general product longevity, although the overall quality of the product is generally defined by its culinary benefits (Mas'ud et al., 2017).

\section{Fatty acids profile}

In general, the results revealed that the total saturated fatty acids and unsaturated fatty acids of MSK oil were about $28 \%$ and $72 \%$, respectively. Unsaturated fatty acids were higher than saturated fatty acids. Oleic acid was the major unsaturated fatty acid, followed by linoleic acid, while stearic acid was the main saturated fatty acid.

Based on Table 2, it can be seen that MSKF oil is rich in oleic and stearic fatty acids. High oleic content indicates that the oil is good for health, while high stearic fatty acid indicates that the oil is stable and tolerant towards rancidity. The high content of stearic fatty acid makes MSK fat has the typical characteristics of a vegetable butter. Besides, it is also rich in linoleic fatty acids, which are also very good for health. This makes MSK a valuable source for producing high-value edible oils, as the values of its refractive index, acid, saponification, and iodine are generally within the standard specifications. Furthermore, MSK fat has a lower IC50 (half maximal inhibitory concentration) value than butylated hydroxytoluene (BHT) as a reference, allowing its ideal application as a functional or enriched food ingredient. In summary, the fat content of MSK makes this oil recommendable to the food, pharmaceutical, and cosmetic industries.

\section{CONCLUSION}

The present study has highlighted the potential of MSKF as a source of food. MSKF contained considerable amounts of carbohydrate, antioxidant components such as polyphenols, carotenoid vitamin $\mathrm{E}$, and ascorbic acid. Stearic acid was the main saturated fatty acid, and oleic acid was the major unsaturated fatty acid. Other than that, it also contained good amounts of calcium, magnesium, potassium, phosphorus, and sodium. Although more research is needed, MSKF which is often considered as a waste seems promising as a food. MSKF can be used in the manufacturing of cakes, cookies and breads, both singly or as a composite with cassava and sweet potato flour. MSKF is expected to help overcome the problem of food 
insecurity in Asia and Africa, which can cause hunger and is feared to occur in the next 35-50 years.

\section{Acknowledgement}

Thanks to the Directorate of Higher Education, Ministry of Research and Technology and Higher Education of Indonesia for a Research Grant that supports the funding of this study with No. Contract of 155/SP2H/LT/DRPM/2019, and we do appreciate and thank the Department of Chemical Engineering, Politeknik Negeri Ujung Pandang, for supporting the laboratory by providing instrument and other equipment for analysis.

\section{Authors' contributions}

FM, the leader of researcher, conceptualised, designed the research, and prepared manuscripts; AR, carried out sample analysis and data collection; MS, conducted research and assisted in the preparation of the manuscript.

\section{Conflict of interest}

The authors have no conflict of interest to be declared.

\section{References}

AOAC (1990). Official methods of Analysis of the Association of Official Analytical Chemists. Association of Official Analytical Chemists, Washington, DC.

Ekpe OO, Umoh IB \& Eka OU (2007). Effect of a typical processing method on the proximate composition and amino acid profile of bush mango seeds (Irvingia gabonensis). Afr $J$ Food Agric Nutr Dev 7(1):2-12.

Elegbede JA, Achoba II \& Richard H (1995). Nutrient composition of mango characteristics of seed kernel from Nigeria. J Food Biochem 19:391-398.
Jahurul M, Zaidul I, Ghafoor K, Al-Juhaimi F, Nyam K, Norulaini N \& Mohd A (2015). Mango (Mangifera indica L.) by-products and their valuable components: A review. Food Chem 183:173-180.

Karnjanawipagul P, Nittayanuntawech W, Rojsanga P \& Suntornsuk L (2010). Analysis of $ß$-carotene in carrot by apectrophotometry. $J$ Pharm Sci 37(1-2):8-16.

Kriengsak T, Unaroj B, Kevin C, Luis C \& David HB (2006). Comparison of ABTS, DPPH, FRAP, and ORAC assays for estimating antioxidant activity from guava fruit extracts. $J$ Food Compos Anal 19:669- 675.

Mas'ud F, Mahendradatta M, Laga A \& Zainal Z (2017). Optimization of mango seed kernel oil extraction using response surface methodology.

Oilseeds \& fats Crops and Lipids 24(5):D503. https://doi.org/10.1051/ocl/2017041

Muchiri D, Mahungu S \& Gituanja S (2012). Studies on mango (Mangifera indica, L.) kernel fat of some Kenyan varieties in Meru. J Am Oil Chem Soc 89(9):1567-1575.

Nzikou JM, Kimbonguila A, Matos L, Loumouamou B, Pambou-Tobi NPG, Ndangui CB, Abena AA, Silou Th, Scher J \& Desobry S (2010). Extraction and characteristics of seed kernel oil from mango (Mangifera indica). Res $J$ Environ Earth Sci 2:31-35.

Odunsi A (2005). Response of laying hens and growing broilers to the dietary inclusion of mango (Mangifera indica L.) seed kernel meal. Trop Anim Health Pro 37(2): 139-150. 